\title{
Identification and purification from the plasma of Type 1 diabetic subjects of a proteolytically active Grp94
}

\section{Evidence that Grp94 is entirely responsible for plasma proteolytic activity}

\author{
A. Pagetta ${ }^{1}$, A. Folda ${ }^{2}$, A. M. Brunati ${ }^{2}$, P. Finotti ${ }^{1}$ \\ ${ }^{1}$ Department of Pharmacology and Anaesthesiology, University of Padova, Padova, Italy \\ ${ }^{2}$ Biomembrane Section, Institute of Neurosciences, CNR, Department of Biochemistry, University of Padova, Padova, Italy
}

\begin{abstract}
Aims/hypothesis. The overall increase in proteolytic activity in diabetes is known to be associated with the development and progression of vascular complications. Our aim was to investigate in detail the molecular nature of this activity in the plasma of Type 1 diabetic subjects. Methods. Plasma of both diabetic and control subjects was subjected to various purification procedures (ion exchange and affinity chromatography, HPLC, immunoprecipitation, electrophoresis, immunoblot and mass analyses) to identify the proteins of interest. Biological activities were measured on specific substrates.

Results. In diabetic but not normal plasma we identified the presence of two heat shock proteins, Grp94 (Glucose-regulated protein94) and HSP70. The higher-than-normal proteolytic activity of Grp94 was: (i) directed against casein, but not against endogenous plasma proteins; (ii) fully and specifically inhibited
\end{abstract}

only by anti-Grp94 polyclonal antibodies; and (iii) coupled with low-level ATPase activity. In addition, ATP binding to Grp94 was able to modulate proteolytic activity. We found that Grp94 in plasma circulates only as high molecular mass homo- and hetero-complexes, the latter mostly formed with IgG to which Grp94 is also linked by tenacious binding. Proteolytically-active Grp94 was purified by immunoprecipitation, which co-immunoprecipitated $\alpha_{1}$ antitrypsin.

Conclusion/interpretation. Our results show the unexpected extracellular location and characteristic biological function of Grp94 even at a late stage of disease. These findings have physiopathological relevance for predicting activation of both autoimmune and inflammatory processes potentially associated with vascular complications. [Diabetologia (2003) 46:996-1006]

Keywords Diabetes mellitus, insulin-dependent, heat shock proteins, peptide hydrolase, blood proteins.
One of the most troublesome aspects of Type 1 (insulin-dependent) diabetes mellitus are early and severe complications, especially those affecting the vascular bed [1], which are the main causes of increased morbidity and mortality in the diabetic population. Although the role of hyperglycaemia in worsening dia-

Received: 9 December 2002 / Revised: 6 February 2003

Published online: 25 June 2003

C) Springer-Verlag 2003

Corresponding author: P. Finotti, Department of Pharmacology and Anaesthesiology, University of Padova, Largo E. Meneghetti 2, 35131 Padova, Italy

E-mail: paola.finotti@unipd.it

Abbreviations: HSP, Heat shock proteins; $\alpha_{1}$ AT, $\alpha_{1}$ antitrypsin; $\mathrm{ER}$, endoplasmic reticulum. betic complications is well established [2], it is unlikely that chronic hyperglycaemia is the only etiopathogenetic factor $[3,4,5]$. Genetic factors also affect the course of complications produced by long-lasting hyperglycaemia: hyperglycaemia-induced oxidative modifications interplay in a complex way with genes $[6,7]$, and a predisposing genetic background could explain the irreversibility of some glucose-induced damage in susceptible patients [8]. Markers for vascular complications, often apparently independent of glycaemic control, are alterations in proteolytic enzyme action $[9,10,11,12]$ and of their inhibitors [9, $13,14]$. Such changes include unbalanced hyperactivation of plasma-clotting enzymes [15], but also an overall increase in proteolytic activity in various tissues and biological fluids $[10,12]$. Thus a higher-than-nor- 
mal proteolytic activity of plasma has been documented in Type 1 diabetic subjects related to an anomalous form of $\alpha_{1}$ antitrypsin ( $\alpha_{1}$ AT) [16], the most important circulating inhibitor of serine proteases. Alterations of the concentration and function of $\alpha_{1}$ AT occur in Type 1 diabetic subjects early in the course of disease and even in the absence of any complications [17]. Since various enzymes could concur differently in determining the overall increase in proteolytic activity of diabetic plasma, we wanted to investigate this issue in detail, by identifying the molecular nature of the substance(s) responsible for this activity. We present the results of an exhaustive investigation carried out on pooled plasma of Type 1 diabetic subjects.

\section{Subjects and methods}

Subjects. Plasma was collected from the heparinized blood of ten Type 1 diabetic subjects (6 women, 4 men), and from six control subjects matched for age and sex. All subjects gave their informed consent for the sampling of blood. Diabetic subjects (mean age \pm SD of $38.2 \pm 10.9$ years, range $20-53$ ) had a mean $( \pm$ SD) duration of diabetes of $12.6( \pm 7.7)$ years, and a mean $( \pm \mathrm{SD}) \mathrm{HbA}_{1 \mathrm{c}}$ value of $8.48 \%( \pm 1.36)$. Control subjects, recruited from personnel and students attending our laboratories, had a mean age $( \pm$ SD) of $35.7 \pm 6.7$ years. All subjects were non-smokers, they did not take any medication (other than insulin for diabetic subjects), nor did they show any clinical or biohumoral evidence of vascular complications.

Purification procedures. Pooled plasma was dialysed overnight on Spectrapor membrane tubing of 15,000 MWCO (A.H. Thomas, Philadelphia, Pa., USA) against two 50-fold volume changes of buffer containing Tris- $\mathrm{HCl} 20 \mathrm{mmol} / \mathrm{l}(\mathrm{pH} \mathrm{7.4)}$. After dialysis, plasma was passed through a DEAE Sephadex A-25 column (Pharmacia LKB, Uppsala, Sweden) equilibrated with the same buffer used for dialysis. Elution of proteins from the column was by a stepwise gradient (constant flow rate of $40 \mathrm{ml} / \mathrm{h}$ ) with the equilibration buffer solution without and with $1 \mathrm{~mol} / \mathrm{l} \mathrm{NaCl}$. Void volume and $1 \mathrm{~mol} / \mathrm{l} \mathrm{NaCl}$ fractions were submitted to ultrafiltration (Centriflo, 25,000 membrane MWCO, Amicon, Danvers, Mass., USA). The $\mathrm{NaCl}$ fraction from the DEAE column was further purified through a Con-A Sepharose 4B column (Amersham Pharmacia Biotech, Uppsala, Sweden), by loading $3.72 \mathrm{mg}$ proteins. Proteins were eluted with the buffer solution (Tris- $\mathrm{HCl} 20 \mathrm{mmol} / \mathrm{l}, \mathrm{NaCl} 0.5 \mathrm{M}, \mathrm{pH} 7.5$ ), without (void volume) and with the addition of $0.5 \mathrm{~mol} / \mathrm{l} \alpha$-D-methylmannoside (to remove Con-A-bound proteins). All chromatographic steps were performed on a fast protein liquid chromatography system (Pharmacia LKB, Uppsala, Sweden).

The $\mathrm{NaCl}$ fraction from the DEAE column was further analysed by reverse-phase HPLC on a Vydac $\mathrm{C}_{4}$ column (Vydac, Hesperia, Calif., USA) with three linear gradient steps of acetonitrile (with addition of $0.05 \%$ TFA): $0-40 \%$ (in $10 \mathrm{~min}$ ), $40-60 \%$ (in $15 \mathrm{~min}$ ) and $60-90 \%$ (in $10 \mathrm{~min}$ ), monitoring the eluate at $220 \mathrm{~nm}$.

Electrophoresis and immunoblotting. Electrophoresis was run on $8.5 \%$ and $10 \%$ polyacrylamide gels, in denaturing (SDS) and non-denaturing conditions, loading 5-10 $\mu \mathrm{g}$ sample proteins, in the absence and presence of reducing treatment. Gels were stained with Coomassie brilliant blue. For immunoblot analysis, proteins $(3-5 \mu \mathrm{g})$ were transferred overnight into a
PVDF membrane (Immobilon, Millipore, Bedford, Mass., USA) and treated with the following primary antibodies in $20 \mathrm{ml}$ of TBS solution: anti-human HSA, $\alpha_{1}$ AT, prothrombin, coagulation Factor X, IgG (all sheep polyclonal antibodies, The Binding Site, Birmingham, UK); HSP70 (rabbit polyclonal), HSP90 (rabbit polyclonal) and Grp94 (rabbit polyclonal, SPA 851, and rat monoclonal, SPA 850) (StressGen Biotechnologies, Victoria, B.C., Canada). Both alkaline phosphatase and horseradish peroxidase conjugated affinity purified IgG were used as secondary antibodies. Negative controls were made with secondary antibodies alone, to confirm the specificity of the immunostaining.

Proteolytic activity. We incubated $\alpha$ casein (Sigma Chemicals, St. Louis, Mo., USA) at a final concentration of $1.1 \mathrm{mg} / \mathrm{ml}$ in Tris- $\mathrm{HCl} 20 \mathrm{mmol} / \mathrm{l}$ (pH 7.4) with $0.37 \mathrm{mg} / \mathrm{ml}$ sample proteins at $37^{\circ} \mathrm{C}$ for $60 \mathrm{~min}$. Aliquots of samples were drawn at intervals of $10 \mathrm{~min}$ and added to a sample buffer mixture containing SDS. Digestion patterns were followed by PAGE [18] at $12.5 \%$ polyacrylamide gel. In experiments for testing the inhibition of proteolytic activity, we preincubated samples with protease inhibitors ( $\alpha_{1}$ AT, antithrombin III, $\alpha_{2}$-macroglobulin, soybean trypsin inhibitors, Sigma Chemicals), ATP (Sigma Chemicals) and anti-human antibodies (anti: HSA, $\alpha_{1}$ AT, IgG, HSP70, Grp94) for $30 \mathrm{~min}$ at $37^{\circ} \mathrm{C}$, before adding casein. The reaction was then followed for $60 \mathrm{~min}$, as indicated above. To test the effects of temperature on proteolytic activity, we heated samples at $39,41,43$ and $45^{\circ} \mathrm{C}$ for $30 \mathrm{~min}$ before following the reaction in the presence of casein, again at $37^{\circ} \mathrm{C}$. For quantitative analyses of proteolytic activity, the density of the casein band (32 kDa), expressed in arbitrary units of its area, was compared, at any time of incubation, with that of its own control (undigested casein, taken as $100 \%$ ). No variation in the control band of undigested casein was noted at any of the indicated incubation times at $37^{\circ} \mathrm{C}$.

We measured the trypsin-like activity of DEAE fractions (3-500 $\mu \mathrm{g} / \mathrm{ml}$ ) on $N \alpha$-benzoyl-DL-arginine- $p$-nitroanilide hydrochloride (BAPNA) substrate, as described [19]. Plasminspecific substrate Chromozym PL (Roche Diagnostics SpA, Basel, Switzerland) was used to test plasmin-like proteases. The incubation medium, at the final volume of $1.3 \mathrm{ml}$, included the buffer solution $(50 \mathrm{mmol} / \mathrm{l}$ Tris-HCL with $0.1 \mathrm{~mol} / \mathrm{l}$ $\mathrm{NaCl}, \mathrm{pH}$ 8.2) with $100 \mathrm{mmol} / \mathrm{l}$ glycine and $0.2 \%$ Tween 20 (Merck, München, Germany), Chromozym PL $(0.136 \mathrm{mg} / \mathrm{ml})$ and sample proteins $(3-30 \mu \mathrm{g} / \mathrm{ml})$. The reaction was followed at room temperature for $3 \mathrm{~min}$ by monitoring the increase in absorbance at $405 \mathrm{~nm}$.

Esterolytic activity. This activity was measured on p-nitrophenyl acetate substrate, as described [20, 21], by monitoring the formation of $p$-nitrophenol at $400 \mathrm{~nm}$. Standard curves were made with non-glycated and glycated HSA $(8.56 \mu \mathrm{mol} / \mathrm{l}$, final concentration). Glycated HSA was from Sigma Chemicals. When activity was measured in the presence of anti-HSA and anti-Grp94 antibodies, we preincubated sample proteins with antibodies (antibody-to-sample weight concentration ratios of $1: 10$ and $1: 100$ ) at $37^{\circ} \mathrm{C}$ for $30 \mathrm{~min}$ before following the reaction by adding the substrate. Non-linear regression analysis (one-phase exponential decay equation) was used for graphing data and calculating statistical parameters (Graph Pad Prism, version 2.0, San Diego, Calif. USA).

ATPase activity. This activity was measured by adding 3,6 and $12 \mu \mathrm{g}$ proteins of both plasma and DEAE fractions to reaction medium containing, in $30 \mu \mathrm{l}$, and at final concentrations: $2.5 \mathrm{mmol} / \mathrm{l}$ Tris-HCl (pH 7.5), $2 \mathrm{mmol} / \mathrm{l} \mathrm{MgCl} 2,2.5 \mathrm{mmol} / \mathrm{l}$ $\mathrm{NaCl}, 0.02 \mathrm{mmol} / \mathrm{l}$ ATP and $25 \mu \mathrm{mol} / 1$ [ $\left.{ }^{32} \mathrm{P}\right] \mathrm{ATP}(2000 \mathrm{cpm} /$ 

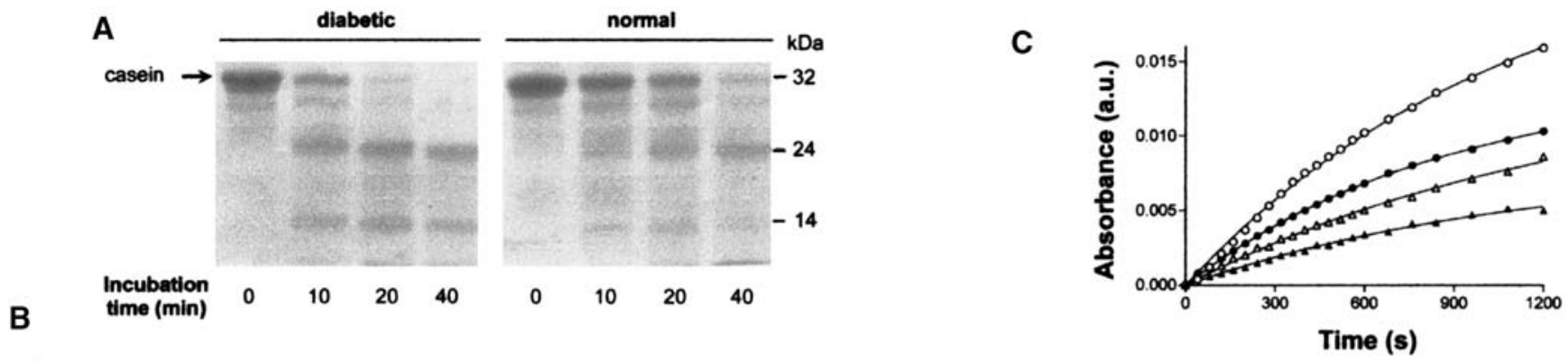

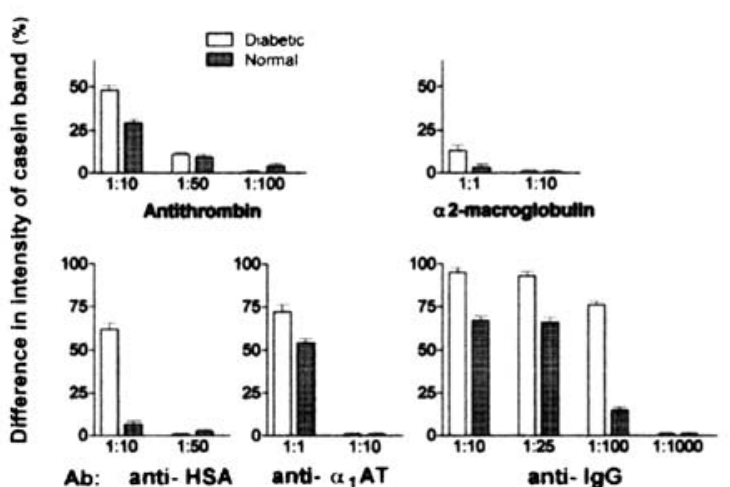

Fig. 1A-D. Biological activities of diabetic plasma and its DEAE fraction. A Proteolytic activity on casein of diabetic and normal DEAE fractions at different times of incubation. Digestion products of casein are shown with molecular masses on right. $10 \mu \mathrm{g}$ proteins were loaded in each lane. B Inhibition of proteolytic activity by protease inhibitors, ATP and antibodies at final concentrations indicated in abscissa (ratios are substance-to-fraction weight protein concentrations). In ordinate axis, inhibition of proteolytic activity, measured after 40-min incubation at $37^{\circ} \mathrm{C}$, expressed as difference of density (in percent) between bands of casein in presence of indicated substance and its absence (control). After 40-min incubation, control values of casein band (referred to the undigested band at time 0 ) are: 0 and $27 \% \pm 5.9$ (means $\pm \mathrm{SD}, n=10$ ), for diabetic and normal DEAE fractions, respectively. (In normal subjects, casein band is not completely digested after $40 \mathrm{~min}$ ). C Esterolytic activities of DEAE fractions in absence and presence of anti-HSA antibodies (antibody-to-fraction weight protein concentration ratio of $1: 10) \bigcirc, \boldsymbol{O}$ : diabetic subjects; $\triangle, \boldsymbol{\Delta}$ normal subjects, in both absence $(\bigcirc, \triangle)$ and presence of antibody $(\boldsymbol{\Lambda}, \mathbf{\Delta}) . p<0.05$, comparisons between intra-group (absence vs presence of antibodies) and inter-group (diabetic vs normal) activities, in absence of antibodies. D ATPase activity of both plasma and DEAE fractions, in diabetic and normal subjects, expressed as pmol of free ${ }^{32} \mathrm{Pi}$. Specific activity is obtained by subtracting spontaneous (basal) liberation of ${ }^{32} \mathrm{Pi}(10 \mathrm{pmol})$ from total. Heights of histograms are means $( \pm$ SD) of at least four independent determinations

pmoles). After incubation at $37^{\circ} \mathrm{C}$ for $2.5,5,10,20$ and $30 \mathrm{~min}$, the reaction was terminated by adding $1.5 \mathrm{ml}$ TCA $(10 \%)$. After centrifugation, the ${ }^{32} \mathrm{Pi}$ in the supernatant was converted to phosphomolybdic complex, extracted with $2.5 \mathrm{ml}$ of isobutanol/toluol (1:1) and evaluated by liquid scintillation [22].

Immunoprecipitation. Pre-clearing of the $\mathrm{NaCl}$ fraction from the DEAE column was carried out by incubating $1.0 \mathrm{ml}(1 \mathrm{mg}$ proteins) with $75 \mu \mathrm{l}$ of Protein A-agarose CL-4B (Sigma Chemicals) for $2.0 \mathrm{~h}$ at $4^{\circ} \mathrm{C}$, followed by centrifugation at
D

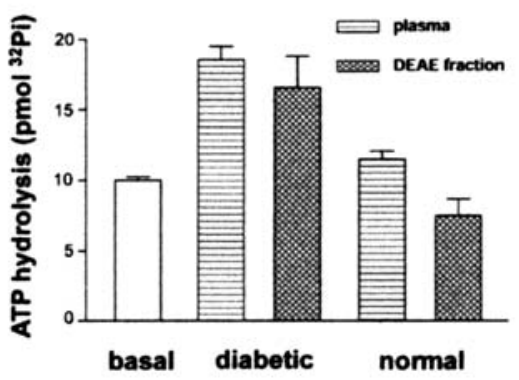

$1500 \times g$ for $10 \mathrm{~min}$. The supernatant was incubated overnight, under slow stirring, with $12.5 \mu \mathrm{g}$ of anti-Grp94 antibodies (rabbit polyclonal $\mathrm{IgG}$, from StressGen). Immunocomplexes were pelletted by incubation with $75 \mu \mathrm{l}$ of Protein A-agarose CL-4B (2.0 h at $4{ }^{\circ} \mathrm{C}$ under slow stirring) and centrifugated. Pellet was washed repeatedly in TBS solution, electrophoresed on SDS-PAGE (10\% gel) with reducing treatment, transferred to a PVDF membrane (Millipore, Bedford, Mass., USA), and probed with antibodies, as specified in the legend to relative figures.

$N$-terminal analysis. Automatic Edman degradation of sample proteins was followed on an Applied Biosystems (Foster City, Calif., USA) sequencer (477A) equipped with an on-line 120A phenylthiohydantoin amino acid analyser. Protein sequence information was obtained from the National Center for Biotechnology Information (NBCI, Bethesda, Maryland) searching by protein sequence alignments (http://www.ncbi.nlm.nih.gov/).

Mass analysis. Data from matrix-assisted desorption ionization time-of-flight (MALDI-TOF) MS of sample solutions were acquired using a TOF Spec-2E spectrometer (Micromass, Manchester, UK) at the Glaxo-Smith Kline Laboratories in Verona (Italy). All spectra were acquired in linear mode using $25 \mathrm{kV}$ acceleration voltage.

\section{Results}

Proteolytic activity of diabetic plasma is not explained by serine proteases. Purification of both diabetic and normal plasma on a DEAE ion-exchange column showed that most of the proteolytic activity was retained in the fraction eluted with $1 \mathrm{~mol} / \mathrm{l} \mathrm{NaCl}$ (henceforth DEAE fraction). At any time of incubation (from 0 to $60 \mathrm{~min}$ ) with casein, the proteolytic activity of the diabetic fraction was much higher than that of the normal fraction, complete digestion of the substrate occurring within $40 \mathrm{~min}$ at $37^{\circ} \mathrm{C}$ (Fig. 1A). Measure- 
ments made on the most common small synthetic substrates for testing serine proteases always gave negative results. Likewise, we were unable to reveal the presence of thrombin, plasmin or coagulation Factor $\mathrm{X}$ in immunoblotting. We then measured the extent of inhibition of proteolytic activity by various protease inhibitors. At the highest concentrations, both $\alpha_{1}$ AT and soybean trypsin inhibitor were completely ineffective, whereas $\alpha_{2}$-macroglobulin yielded a maximal inhibition of $13 \%$ (Fig. 1B). Antithrombin showed a concentration-dependent inhibition over a narrow range of concentrations, reaching a maximal inhibition of $48 \%$ (Fig. 1B). These results excluded the possibility that serine proteases were mainly responsible for the proteolytic activity of diabetic plasma.

We also tested the possibility that glycation had conferred on HSA in new, so far undetected, proteolytic activity. We measured the esterase activity of both plasma and the DEAE fraction, and found that it was much higher in diabetic than in normal subjects (Fig. 1C). However, we verified that HSA glycated "in vitro" did not display any proteolytic activity on casein, while on its own it exhibited esterase activity overlapping that of the DEAE fraction of diabetic subjects. Thus, proteolytic and esterase activities in diabetic plasma are driven by different substances.

Proteolytic activity is coupled with ATPase activity. Since the protease activity of diabetic plasma has been closely associated with a higher-than-normal ATPasestimulating property [16], we investigated whether diabetic plasma also has intrinsic, still undetected, ATPase activity. Using radioactive Pi measurement, low but constant ATPase activity was detected in diabetic, but not normal, plasma and DEAE fraction. Specific ATP hydrolysis (18.55 and $16.55 \mathrm{pmol}{ }^{32} \mathrm{Pi}$ for plasma and the DEAE fraction, respectively) was only observed at a protein concentration of about $200 \mu \mathrm{g} / \mathrm{ml}$, and after $5 \mathrm{~min}$ of incubation at $37^{\circ} \mathrm{C}$ (Fig. 1D). The finding that specific ATPase activity was dependent on neither protein concentration nor time of incubation strongly suggested that ATPase has a regulatory rather than transporting property. By submitting the same sample of the DEAE fraction to measurements of both ATPase and proteolytic activities, we noted that the increase in specific ATP hydrolysis was closely coupled with reduction in proteolytic activity. Accordingly, the addition of ATP (1 and $3 \mathrm{mmol} / \mathrm{l}$, final concentrations) to the incubation assay for proteolytic activity caused a slight, concentrationdependent inhibition of activity of the diabetic but not normal, DEAE fraction, with maximum inhibition of $20 \%$ at $3 \mathrm{mmol} / \mathrm{l}$ ATP (Fig. 1B). These results suggested that proteolytic and ATPase activities are coupled.

Heat shock proteins circulate in the plasma of diabetic but not normal subjects. We investigated whether

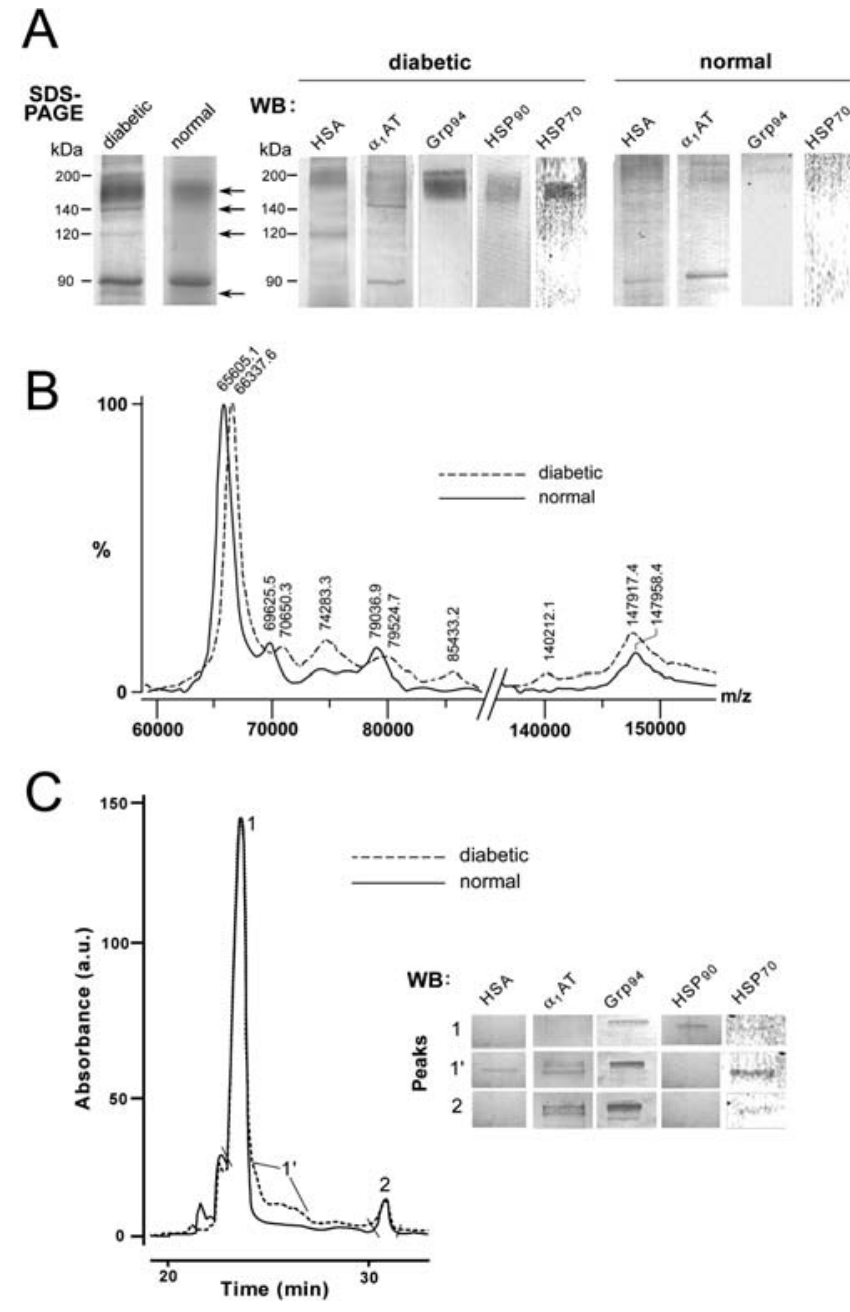

Fig. 2A-C. HSPs among plasma proteins of diabetic subjects. A SDS-PAGE (10\% gel) and Western blotting of diabetic and normal DEAE fractions with bands at molecular masses above $70 \mathrm{kDa}$ (arrows). Corresponding positivities to indicated antibodies on right. The main positivities for HSA and $\alpha_{1}$ AT are at $65 \mathrm{kDa}$ and $55 \mathrm{kDa}$, respectively (not shown). B Mass spectra of diabetic and normal DEAE fractions, with peaks at masses from 60,000 to 150,000 Da. C HPLC chromatograms of diabetic and normal DEAE fractions with the shoulder to peak 1 (peak $1^{\prime}$ ). $130 \mu \mathrm{g}$ proteins were loaded. Right: panels of Western blotting showing only the near-cathode area, with positivities to indicated substances. Peak 1 almost entirely accounts for plasma HSA, whereas in peak 2 concentrates plasma $\alpha_{1} \mathrm{AT}$ (positivities of the main bands of both proteins not shown)

HSPs, which can display both proteolytic and ATPase activities [23, 24], were responsible for the anomalous biological activities found in diabetic plasma. SDSPAGE showed marked differences between diabetic and normal DEAE fractions, in number and mobility of bands, mostly at high molecular masses (Fig. 2A, arrows). This picture was confirmed by mass analysis which further disclosed significant differences (Fig. 2B). The increase in mass of about $732 \mathrm{Da}$ assigned to the HSA peak in diabetic subjects $(66337.6 \mathrm{Da})$ is consistent with the condensation of four glucose molecules per HSA molecule, due to 
glycation. The peaks at 74283,85433 and $140212 \mathrm{Da}$ appeared only in the diabetic fraction, whereas the 147900-Da peak, present in both chromatograms, had in the diabetic fraction an area $100 \%$ greater than that of the corresponding normal peak (Fig. 2B) - a difference mirrored in SDS-PAGE by the band at about $150 \mathrm{kDa}$, which was much more diffuse and intense in the diabetic fraction (Fig. 2A, left panel). Immunoblot analysis identified the bands peculiar to the diabetic fraction, with masses between 140 and $200 \mathrm{kDa}$, as being due to: $\alpha_{1}$ AT (140 kDa) (Fig. 2A), IgG (147 kDa) and HSPs (Fig. 2A, right panel). Positivity for Grp94 far exceeded that observed for other HSPs, and was seen in two broad bands covering the region from 150 to $200 \mathrm{kDa}$. HSP70 migrated in a band slightly below Grp94 and HSP90 bands. No positivity for any of these HSPs was found in the normal fraction (Fig. 2A).

We further analysed the diabetic and normal DEAE fractions in reverse-phase HPLC (Fig. 2C) which, despite denaturation of proteins, proved useful in separating and concentrating HSPs. Immunoblot and mass analyses of HPLC peaks assigned to peak 1 of the diabetic DEAE fraction monomeric forms of HSA, structurally similar to HSA in peak 1 of the normal fraction. Both heavier (glycated) forms of HSA $(67429 \mathrm{Da})$ and proteins with masses higher than $70,000 \mathrm{Da}$ (which strongly immunoreacted with antiGrp94 and anti-HSP70 antibodies), eluted in peak 1' (Fig. 2C, right). Due to the presence of these HSPs, tryptic digestion of peak 1 together with peak 1' yielded an electrophoretic pattern which, in number and mobility of the bands, differed from that obtained after digestion of peak 1 only. Grp94 began to elute distinctly in peak $1^{\prime}$ but concentrated in peak 2 , where it focused in two sharp bands near the cathode (Fig. 2C, right). HSP90 was detected only in peak 1 and HSP70 in peak 1' (Fig. 2C, right). Thus, Grp94 appeared to be the most hydrophobic of the HSPs. Interestingly, in both peaks $1^{\prime}$ and 2, the Grp94-positive bands also cross-reacted with anti- $\alpha_{1}$ AT antibodies (Fig. 2C, right).

Grp94 entirely accounts for the proteolytic activity of diabetic plasma. Since electrophoretic and mass analyses indicated that HSPs were present as high molecular-mass complexes, which also cross-reacted with plasma $\alpha_{1}$ AT, HSA (Fig. 2A) and IgG, we investigated whether such HSP-protein complexes were responsible for proteolytic activity. We thus tested the effect of specific antibodies on activity of the DEAE fraction. Anti-HSP70 antibodies did not affect proteolytic activity at all, whereas anti- $\alpha_{1}$ AT antibodies caused an inhibition of $72 \%$ only at the highest concentration (1:1 ratio) (Fig. 1B). By using anti-HSA antibodies we showed a significant inhibition of $62 \%$ at the concentration ratio of 1:10 (Fig. 1B). An even more significant, concentration-dependent inhibitory effect was noted with anti-IgG antibodies which gave inhibitions of $97 \%, 95 \%$ and $78 \%$ at concentration ratios of $1: 10$, 1:25 and 1:100, respectively (Fig. 1B). However, it was only with anti-Grp94 antibodies that we observed $100 \%$ inhibition of proteolytic activity up to the concentration ratio of 1:200 (Fig. 1B). Inhibition progressively decreased as the concentration of antibodies was lowered, being $91 \%, 86 \%, 78 \%$ and $32 \%$ at ratios of $1: 400,1: 800,1: 1000$ and 1:2500, respectively. At 1:5000, activity was completely restored (Fig. 1B). The inhibitory effect was displayed only by polyclonal but not monoclonal anti-Grp94 antibodies.

We tested effectiveness of anti-Grp94 antibodies also in the assay for esterase activity: the concentration which completely inhibited protease activity (1:100 ratio) only inhibited esterase activity by $21 \%$. Similarly, anti-HSA antibodies, at the same concentration which inhibited proteolytic activity by $62 \%$, inhibited esterolytic activity only by $38 \%$ (Fig. 1C). Instead, in the normal DEAE fraction, anti-Grp94 antibodies were completely ineffective in reducing the proteolytic activity, whereas anti- $\alpha_{1}$ AT and anti-IgG antibodies caused much less inhibition than that observed in the diabetic DEAE fraction (Fig. 1B). AntiHSA antibodies were also completely ineffective in inhibiting the proteolytic activity of the normal DEAE fraction, whereas they were able to reduce esterolytic activity by $52 \%$ at the concentration ratio of $1: 10$ (Fig. 1C). These results further confirmed that proteolytic activity in diabetic and normal plasma is sustained by different substances.

Grp94 circulates mostly complexed with IgG. The immunopositivity for Grp94 visible only in bands at high molecular masses indicated the presence of homocomplexes and hetero-complexes of Grp94, as also suggested by inhibition of activity seen with anti-IgG and, to a lesser extent, anti-HSA antibodies. By submitting the DEAE fraction to reducing treatment in SDS-PAGE, we observed that the more cathodal band of Grp94 (about $200 \mathrm{kDa}$ ) was only partially converted to monomer of $100 \mathrm{kDa}$ (Fig. 3A, lanes on right), and a residual positivity remained in a band of about $150 \mathrm{kDa}$, suggestive of resistant complexes (Fig. 3A, arrow). Since this band also cross-reacted with antiIgG antibodies, we submitted the DEAE fraction to pre-clearing with Protein A to remove IgG, both free and associated with Grp94. This procedure led to a marked reduction in the $200-\mathrm{kDa}$ Grp94-positive band in the supernatant (Fig. 3C, lane on left in the left panel), suggesting significant removal of IgG-linked Grp94. Indeed, we found a significant concentration of Grp94 in the pellet. First, it was recovered in the 150-kDa band (Fig. 3C, left panel, lane on right: arrow) which cross-reacted with anti-IgG antibodies, whose unique $\mathrm{N}$ terminus gave the sequence EVQLLESDD, identified as that of the IgG heavychain variable region. Thus, part of pelletted Grp94 
A
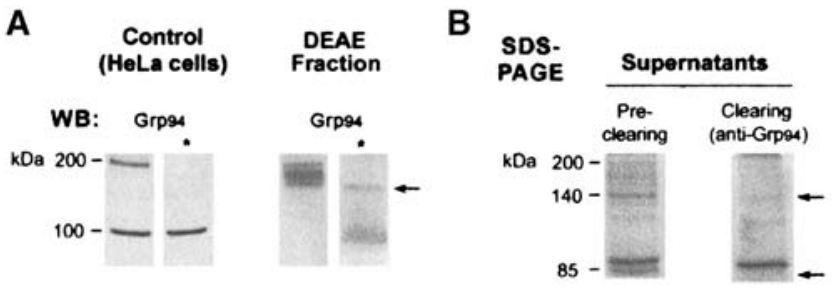

C

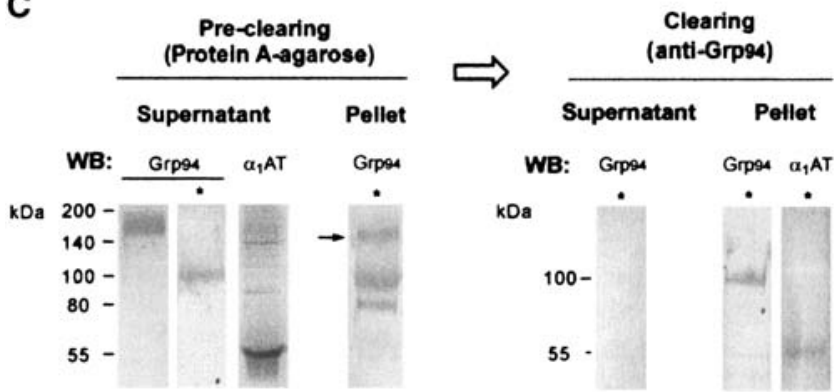

Fig. 3A-C. Nature of circulating Grp94 complexes. A Grp94 expressed in whole HeLa cell lysate (control) and diabetic DEAE fraction were electrophoresed $(10 \mu \mathrm{g} / \mathrm{lane})$ on $10 \%$ SDS-polyacrylamide gel, both in absence and presence of reducing conditions (asterisks above lanes), Western blotted and probed with anti-Grp94 monoclonal antibodies. Arrow marks Grp94 positive band at $150 \mathrm{kDa}$. B SDS-PAGE (10\% gel) of supernatants after pre-clearing and clearing steps (with antiGrp94 polyclonal antibodies). The band above the $85-\mathrm{kDa}$ band $(90 \mathrm{kDa})$ immunoreacts only with anti $\alpha_{1}$ AT polyclonal antibodies (as in Fig. 2A). Arrows mark bands no longer visible after immunoprecipitation. C Both supernatant and pellet after pre-clearing and clearing steps electrophoresed in SDS polyacrylamide gel (10\%), both in absence and presence of reducing conditions (asterisks above lanes), Western blotted and probed with both anti- $\alpha_{1}$ AT polyclonal and anti-Grp94 monoclonal antibodies. In the pellet lane, arrow marks the same band as in A, containing a Grp94-positive IgG heavy chain. Right: co-immunoprecipitation of $\alpha_{1}$ AT with anti-Grp94 polyclonal antibodies

was inextricably linked to $\mathrm{IgG}$, giving rise to a fusion protein. Second, most IgG-complexed Grp94 was pelletted as disulfide-linked complexes since, after reducing treatment, it dissociated from IgG appearing as free Grp94 at both $100 \mathrm{kDa}$ (monomer) and $80 \mathrm{kDa}$ (faster migrating form of the monomer) (Fig. 3C, left panel, lane on right). We could not measure any activity in the pellet because of the Protein-A Sepharose, whereas in the supernatant it was apparently the same as that of the DEAE fraction. Activity in the supernatant was again fully $(100 \%)$ inhibited by anti-Grp94 antibodies up to the concentration ratio of 1:100. Inhibitions of $83 \%, 75 \%$ and $32 \%$ were observed at ratios of 1:200, 1:400 and 1:1000, respectively. Activity was completely restored at 1:2500, a result which points to the apparently reduced (halved) inhibitory capacity by anti-Grp94 antibodies with respect to what was observed in the DEAE fraction. Since the overall Grp94 concentration in the supernatant was much lower than that in the starting DEAE fraction, the reduced sensitivity to antibody inhibition could be due to removal of $\operatorname{IgG}$, both free and linked to Grp94, which favoured the disclosure of new active sites on Grp94, leading to its purification and concentration. Consistent with this possibility, we showed that the $200-\mathrm{kDa}$ band of Grp94 in the supernatant was formed only of Grp94 dimers, converted to monomer by reducing treatment (Fig. 3C, left panel).

We showed a marked reduction in proteolytic activity, together with an increase in Grp94 aggregates, after heating both the DEAE fraction and the preclearing supernatant to $45^{\circ} \mathrm{C}$. Specifically, activity began to decrease already at $39^{\circ} \mathrm{C}$, and disappeared at $43^{\circ} \mathrm{C}$. Instead, the normal DEAE fraction was still active after heating at $39^{\circ} \mathrm{C}$, and activity disappeared completely only at $45^{\circ} \mathrm{C}$. We tested whether, besides the exogenous substrate of casein, also the most represented and physiologically important plasma proteins (HSA and $\alpha_{1}$ AT), were substrates for the proteolytic activity of Grp94. We thus incubated the DEAE fraction at various temperatures $\left(25,37,39\right.$ and $\left.40^{\circ} \mathrm{C}\right)$ over a period lasting up to $24 \mathrm{~h}$ and then we followed proteolytic degradation of the main bands of HSA and $\alpha_{1}$ AT in the DEAE fraction by SDS-PAGE and immunoblotting. We did not find any modifications of electrophoretic patterns consistent with proteolysis of these proteins. Similarly, no autoproteolytic activity of Grp94 was observed at $37^{\circ} \mathrm{C}$ or after repeated freeze/thaw cycles of samples.

Grp94 binding and release during substrate digestion. We set up experiments to detect the role played by Grp94 in the proteolytic degradation of casein. For this purpose, the supernatant (from the pre-clearing step) was incubated, with and without casein, in both the absence and presence of those substances and conditions which were effective in inhibiting proteolytic activity, such as anti-HSA, anti- $\alpha_{1} A T$, anti-IgG and anti-Grp94 polyclonal antibodies, ATP, and heating at $43^{\circ} \mathrm{C}$. Changes were followed by SDS-PAGE for Grp94-positive bands, together with those of the substrate.

After incubation with both anti-HSA and anti- $\alpha_{1}$ AT antibodies, or heating, we did not find any changes in the electrophoretic patterns of the supernatant (Fig. 4A). Incubation with both anti-Grp94 antibodies and ATP caused disappearance of a band at $85 \mathrm{kDa}$ (Fig. 4A), already identified as peculiar to the electrophoretic pattern of the diabetic DEAE fraction (Fig. 2A). In the presence of casein, modifications of the electrophoretic pattern of the supernatant were followed at each time of incubation simultaneously with those of the casein substrate (Fig. 4B). It was thus apparent that, at the beginning of digestion (time zero, undigested casein), the $85-\mathrm{kDa}$ band was not visible at all, whereas it reappeared as digestion progressed, being clearly visibile after digestion was completed (Fig. 4B, left panel). With the addition of anti-Grp94 antibodies, the $85-\mathrm{kDa}$ band was visible only at those 
A

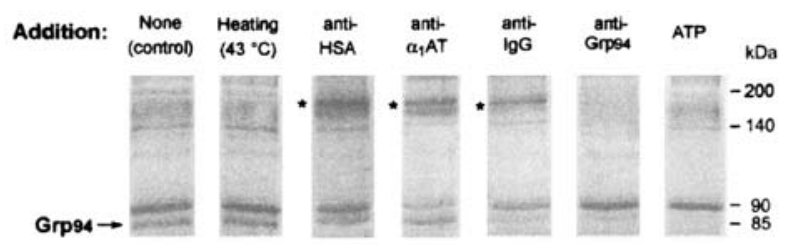

\section{B}

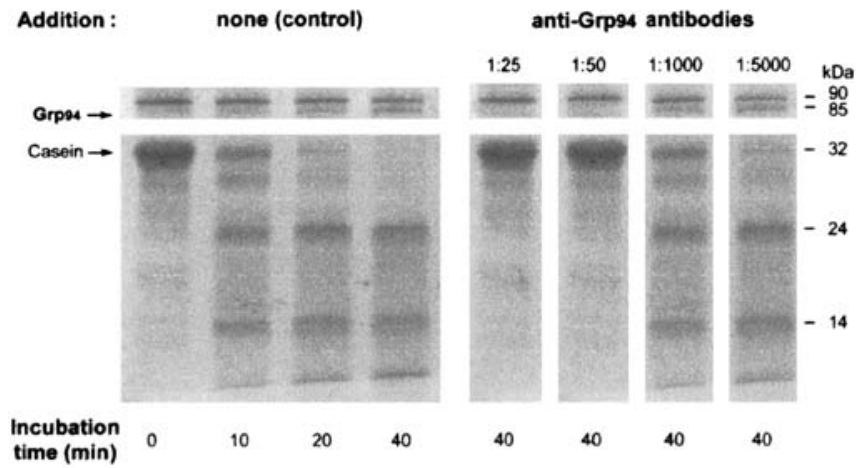

Fig. 4A, B. Grp94 binding to both ATP and anti-Grp94 antibodies prevents binding to casein. A Supernatant from preclearing incubated for $30 \mathrm{~min}$ at $37^{\circ} \mathrm{C}$ in absence (control) and presence of indicated substances/temperature and loaded on $10 \%$ polyacrylamide gel in denaturing conditions (10 $\mu \mathrm{g}$ proteins/lane). Anti-HSA, anti- $\alpha_{1}$ AT and anti-IgG antibodies were used at the final 1:10, antibody-to-supernatant, protein concentration ratio (w:w). Anti-Grp94 antibodies were at the final $1: 25$ concentration ratio, ATP at $3 \mathrm{mmol} / \mathrm{l}$. Only the part of gel with modifications of the electrophoretic pattern is shown. Asterisks on lanes mark IgG region (about $150 \mathrm{kDa}$ ) densely stained because of a higher concentration of antibodies (1:10 ratio). B Supernatant from pre-clearing was incubated as above in the absence (control, left panel) and presence (right panel) of indicated concentrations of anti-Grp94 antibodies. At each antibody concentration, only the lane after 40 min incubation is shown, which represents the condition of maximal digestion of substrate. In both panels, above each lane of casein digestion is the corresponding electrophoretic pattern in the preclearing supernatant at between 85 and $90-\mathrm{kDa}$

concentrations of the antibody which partially inhibited $(1: 1000)$ or did not inhibit $(1: 5000)$ proteolytic activity (Fig. 4B, right panel), the resulting pattern being in this case similar to that of the corresponding control (i.e., absence of antibody) at each time of incubation. At inhibitory concentrations of the antibody (1:50 and $1: 25$ ratios) casein did not undergo any digestion even after $40 \mathrm{~min}$. In the presence of $3 \mathrm{mmol} / \mathrm{l} \mathrm{ATP,} \mathrm{the}$ $85-\mathrm{kDa}$ band again disappeared whereas the casein band remained intact. Specifically, digestion of the casein band was inhibited by about $80 \%$, a value much greater than that observed at the same ATP concentration with the DEAE fraction (Fig. 1B). This significant increase in inhibition by ATP could be attributable to disclosure of additional nucleotide binding sites on N-terminus of the Grp94 molecule after removal of IgG by pre-clearing. N-terminal analysis of the $85-\mathrm{kDa}$ band gave the unique $\mathrm{N}$-terminus of human Grp94 (DDEVXVD). This confirmed that Grp94, in the absence of both ATP and anti-Grp94 antibodies, is actually involved in cycling binding to and release from the substrate, coupled with casein digestion.

Grp94 also immunoprecipitates complexed with $\alpha 1 A T$. As conclusive proof that proteolytic activity was due to Grp94, we submitted the supernatant from preclearing step to immunoprecipitation with anti-Grp94 antibodies (clearing step) (Fig. 3C, right panel). The resulting supernatant was completely cleared of Grp94 and also lacked any proteolytic activity, whereas Grp94 was recovered in the pellet as a free monomer in reducing conditions (Fig. 3C, right panel). We noted that, besides the $85-\mathrm{kDa}$ band, also the band at $140 \mathrm{kDa}$, which was clearly visible in the pre-clearing supernatant, disappeared in the electrophoretic pattern of the supernatant after immunoprecipitation (Fig. 3B, arrows). Since the latter band always immunoreacted with anti- $\alpha_{1}$ AT but not anti-Grp94 antibodies (Fig. 2A), we investigated whether $\alpha_{1}$ AT was complexed with Grp94. Anti- $\alpha_{1}$ AT antibodies tested in the pellet of the clearing step gave specific immunostaining with $\alpha_{1}$ AT in a band running at the expected mass of $\alpha_{1}$ AT at about $55 \mathrm{kDa}$ (Fig. $3 \mathrm{C}$, right panel). This result clearly proved that proteolytically active Grp94 does circulate complexed with $\alpha_{1}$ AT. Breakage of disulfide bridges by reducing treatment leads to the separation of the two proteins which can thus migrate at expected individual molecular masses (Fig. 3C, right panel).

Proteolytically active Grp94 appears to lack glycosylation. We further investigated the nature of circulating Grp94 by passing the DEAE fraction through a Con-A Sepharose column. Retention is expected to occur for the normal (i.e., glycosylated) form of Grp94, which would thus elute with $\alpha$-D-methylmannoside. Contrary to this behaviour, Grp94 in the DEAE fraction eluted entirely as unretained material in the void volume, in two poorly resolved peaks (Fig. 5A). Both possessed significant proteolytic activity, although peak 2 displayed a higher degree of activity than peak 1 (Fig. 5B). In this respect, peak 2 also was more active than the DEAE fraction. The peak eluting with $\alpha$-D-methylmannoside (peak 3) did not show any proteolytic activity (Fig. 5B), nor any positivity for Grp94 in immunoblotting (Fig. 5A). In both peaks 1 and 2, Grp94 was present in two broad bands as those identified at the same molecular masses of about 150 and $200 \mathrm{kDa}$, in the DEAE fraction (Fig. 3A).

Anti-Grp94 antibodies inhibited proteolytic activity in both peaks, although $100 \%$ inhibition was observed at the antibody-to-peak protein concentration ratio of 1:50 in peak 1, but only at 1:25 in peak 2 . At 1:100, antibodies still inhibited activity in peak 1 by $20 \%$ (af- 
A
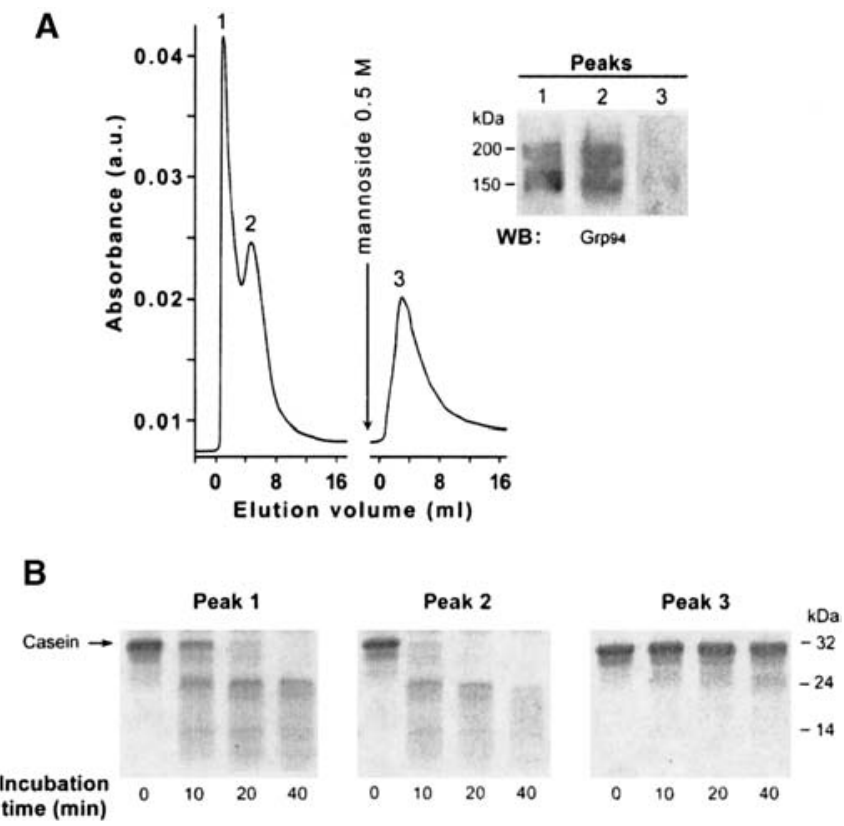

Fig. 5A, B. Characteristics of Grp94 purified through Con-A Sepharose column. A Elution profile of diabetic DEAE fraction from the column. Peaks 1 and 2 (protein concentrations $0.35 \mathrm{mg} / \mathrm{ml}$ and $0.22 \mathrm{mg} / \mathrm{ml}$, respectively) eluted with void volume. Peak $3(0.194 \mathrm{mg} / \mathrm{ml})$ contained retention material. Peak proteins electrophoresed on SDS-PAGE (8.5\% polyacrylamide gel without reducing conditions), Western blotted and probed with monoclonal anti-Grp94 antibodies (right). B Proteolytic activity of peaks eluted from column tested on casein at different times of incubation as specified under "Methods"

ter 40 min incubation with casein), but were ineffective in peak 2. With respect to the DEAE fraction, in peak 2 there was a marked reduction in sensitivity to anti-Grp94 antibodies, probably due to the increased concentration of active Grp94, as suggested by immunostaining of the $200-\mathrm{kDa}$ band (Fig. 5A, right) or to a higher degree of purification after removal of interfering (more glycosylated?) proteins which concur to form aggregates with Grp94.

\section{Discussion}

HSPs have recently attracted much attention because of their involvement in immunological processes [25, 26]. In particular, a crucial role has been attributed to both cytoplasmic HSP70 and, mostly, the ER-resident chaperone Grp94, in binding and delivering antigenic peptides to the MHC class I processing pathway [27, $28,29,30]$. This mechanism, responsible for stimulation of both humoral and cellular immune responses $[26,27,31]$, is common to a variety of inflammatory and autoimmune diseases [25, 30, 32], including diabetes $[33,34]$. Abundant experimental evidence exists supporting the theoretical model that necrotic release of intracellular HSPs, especially Grp94, can deliver immunogenic signals to immune cells. However, any demonstration that such an immune regulatory mechanism actually occurs "in vivo", in response to pathological cell death, has not yet been offered. Our data support this mechanism, showing the "in vivo" extracellular location of HSPs, mostly Grp94, in the plasma of Type 1 diabetic but not normal subjects. The fact that such a result has been observed in diabetic subjects at a time when beta-cell destruction is considered to be complete (after a mean duration of diabetes of 12 years), strongly suggests that the mechanism(s) leading to extracellular liberation of HSPs are still operating, presumably involving cells other than pancreatic beta cells.

We offer several lines of evidence to show that this Grp94 has structural and functional properties, both shared with and distinct from those described for any so far purified preparations of HSPs, in particular Grp94. First and most important is the peculiar, intrinsic proteolytic activity which is displayed in an assay using casein as a generic protein substrate, and is detected as early as $10 \mathrm{~min}$ in the incubation assay at $37^{\circ} \mathrm{C}$, the substrate being completely degraded within $40 \mathrm{~min}$. These characteristics resemble more closely those recently described for some mammalian serine proteases $[18,35]$ rather than overlapping those described for purified Grp94 [36]. However, the enzyme activity of plasma Grp94 is by far the most intense measured for any HSP in "in vitro" assays. Moreover, it also explains the entire proteolytic activity of diabetic plasma. Of particular interest was the result that activity is specifically and fully inhibited only by antiGrp94 antibodies, as shown by the titration curve with scalar concentration of the antibody which, at concentrations as low as $0.37 \mu \mathrm{g} / \mathrm{ml}$, still inhibited activity in the DEAE fraction by $80 \%$. Depletion of Grp94 by immunoprecipitation abolished any proteolytic activity. This represents a cogent proof that Grp94 itself is responsible for proteolytic activity. Blockade by antiGrp94 antibodies implies that antigenic sites on Grp94 either overlap or are close to the protease active site(s). The latter hypothesis fits better our results, given that only polyclonal anti-Grp94 antibodies (developed against a C-terminal synthetic peptide as the immunogen, from StressGen), but not monoclonal antibodies (produced against the entire molecule of human Grp94, from StressGen), turned out to be effective in blocking activity. Thus, monoclonal antibodies could still recognize plasma Grp94 by binding to its antigenic site(s) (as revealed by immunoblot analysis), but leave the protease active site free to bind the substrate. This would imply that the protease active site is located in C-terminus of Grp94. This possibility is further supported by results showing that proteolytic activity was greatly reduced or even abolished in heating conditions. It is known that heating increases the formation of Grp94 aggregates [37] and that domains involved in formation of both homodimers and hetero-complexes of Grp94 are located in 
its C-terminus [38, 39]. Thus, when aggregation tendency is enhanced, the protease active site is likely closed off or masked. An additional proof showing that the protease active site in Grp94 is located in its C-terminus, comes from results of experiments with ATP. ATPase activity of plasma Grp94 shows characteristics similar to those described for purified forms of Grp94 in "in vitro" assays [23, 24]. Indeed, it exceeds the spontaneous liberation of ATP by a small factor, and it does not vary with either protein concentration or time of incubation [24]. We observed that ATP binding to Grp94 caused inhibition of proteolytic activity. It is known that the ATP binding site on Grp94 is located on its N-terminus, and that ATP binding to Grp94 causes conformational changes in the molecule which indirectly affects structure of the C-terminal region $[24,40]$. Thus, the inhibition of activity that we observed with ATP, at variance with that caused by polyclonal antibodies, is the consequence of the indirect regulatory mechanism of ATP on the protease active site on Grp94. We also cannot exclude that anti-Grp94 polyclonal antibodies block proteolytic activity since on their own they recognize and bind structurally modified epitopes on Grp94 better than monoclonal antibodies. Grp94 in diabetic plasma shows a significant structural modification with respect to known purified preparations of intracellular Grp94, which binds to concanavalin A [41, 42]. In our experiments, Grp94 lacks any affinity for Con-A Sepharose column, which is consistent with either loss or masking of the high-mannose glycosylation motif.

Our results indicate that Grp94 in the plasma of diabetic subjects is exclusively present as high molecular mass homo-complexes and hetero-complexes. We were able to identify Grp94 as monomer in SDSPAGE only after reducing treatment. Hetero-complexes of Grp94 are formed with IgG and, to a lesser extent, HSA. Plasma Grp94 is bound to IgG in a complex manner. Experiments of pre-clearing with Protein-A showed that, whereas part of Grp94 is only weakly bound to $\mathrm{IgG}$, for most part it forms tenacious binding apparently giving rise to a $150-\mathrm{kDa}$ fusion protein with the $\operatorname{IgG}$ heavy chain. Further studies are necessary to identify the nature and the precise immunological meaning of Grp94 binding to single heavy chain of IgG. In cell-culture experiments it has been shown that intracellular Grp94, together with other stress proteins, is often linked with unassembled Ig chains [43].

Therefore, Grp94 binding to IgG is the expression of a complex, generalised activation of immune processes. An autoimmune mechanism is likely responsible for the extracellular liberation of complexed forms of Grp94; this, in turn, further activates the immune system because of its immunogenic potential.

At variance with Grp94-IgG complexes, which have immunological relevance in diabetes, the com- plexes of Grp94 with HSA seem to be less specific. Grp94 binding to HSA is the consequence of both the extensive binding capacity of HSA and the chaperone property of Grp94. The fact that Grp94 almost exclusively circulates in plasma complexed with $\operatorname{IgG}$ and HSA accounts for the inhibition of proteolytic activity observed with anti-HSA, and mostly anti-IgG antibodies. However, this inhibition can be explained only in terms of an aspecific mechanism of steric hindrance of the protease active site in Grp94 once the antibody has bound to antigenic sites.

By experiments of immunoprecipitation we obtained purification of proteolytically active Grp94, which not only circulates as dimers but also, and more importantly, as complexed with $\alpha_{1}$ AT. This complex has a mass of $140 \mathrm{kDa}$ and appeared in SDS-PAGE as a band which immunoreacted only with anti- $\alpha_{1}$ AT antibodies. The mass of $140 \mathrm{kDa}$ would fit the $1: 1$ Grp94-to- $\alpha_{1}$ AT complex, which is resolved in its two components by differential immunostaining of the immunoprecipitate. The physiopathological meaning of this complex is at present lacking, although one would anticipate a possible role in stimulating immune responses, similarly to that observed with Grp94-peptide complexes [30, 44].

In conclusion, the finding that Grp94 is markedly increased in plasma of Type 1 diabetic subjects and has a peculiar proteolytic activity, is of physiopathological relevance for predicting the activation of autoimmune and inflammatory reactions potentially involved in vascular damage. Our purification procedures carried out on pooled plasma may have masked important individual differences in Grp94 concentrations and properties, possibly related to other variables linked to the disease.

Acknowledgements. We would like to thank Prof. G.A. Danieli for his helpful discussion of the manuscript, Dr. P. Polverino De Laureto and Dr. E. Frare of Centro di Ricerca Interdipartimentale per le Biotecnologie Innovative (CRIBI, Padova) for $\mathrm{N}$-terminal sequences.

This work was supported by MURST (Ministero dell'Università e della Ricerca Scientifica e Tecnologica) grants of ex$60 \%$ and by CNR (Targeted Project on Biotechnology).

\section{References}

1. Donnelly R, Emslie-Smith AM, Gardner D, Morris AD (2000) Vascular complications of diabetes. $\mathrm{Br}$ Med J 320:1062-1066

2. Yamashita T (1995) Increased transendothelial permeation of albumin by high glucose concentration. Metabolism 44:739-744

3. Microalbuminuria Collaborative Study Group, UK (1995) Intensive therapy and progression to clinical albuminuria in patients with insulin dependent diabetes mellitus and microalbuminuria. Br Med J 311:973-977

4. Marre M (1999) Genetics and the prediction of complications in type 1 diabetes. Diabetes Care S2:B53-B58 
5. Rogus JJ, Warram JH, Krolewski AS (2002) Genetic studies of late diabetic complications. The overlooked importance of diabetes duration before complication onset. Diabetes 51:1655-1662

6. Atkinson M, Eisenbarth GS (2001) Type 1 diabetes: new perspectives on disease pathogenesis and treatment. Lancet 358:221-229

7. Du XL, Sui GZ, Stockklauser-Färber K et al. (1998) Induction of apoptosis by high proinsulin and glucose in cultured human umbelical vein endothelial cells is mediated by reactive oxygen species. Diabetologia 41:249-256

8. Fornoni A, Striker LJ, Zheng F, Striker GE (2002) Reversibility of glucose-induced changes in mesangial cell extracellular matrix depends on the genetic background. Diabetes 51:499-505

9. Finotti P, Piccoli A, Carraro P (1992) Alteration of plasma proteinase-antiproteinase system in type 1 diabetic patients. Influence of sex and relationship with metabolic control. Diabets Res Clin Pract 18:35-42

10. Raghotama C, Rao P (1996) Degradation of glycated hemoglobin by erythrocytic proteolytic enzymes. Clin Chim Acta 245:201-208

11. Yamamoto H, Maake C, Murphy LJ (1999) Enhanced proteolytic activity directed against the N-terminal of IGF-I in diabetic rats. J Endocrinol 162:243-250

12. Shinada M, Akdeniz A, Panagiotopoulos S, Jerums G, Bach LA (2000) Proteolysis of insulin-like growth factorbinding protein-3 is increased in urine from patients with diabetic nephropathy. J Clin Endocrinol 85:1163-1169

13. Carmassi F, Morale M, Puccetti R et al. (1992) Coagulation and fibrinolytic system impairment in insulin dependent diabetes mellitus. Thromb Res 67: 643-654

14. Roberts RC, Hall PK, Nikolai TF, McKenzie AK (1986) Reduced trypsin binding capacity of $\alpha_{2}$-macroglobulin in diabetes. Clin Chim Acta 154:85-101

15. Carr ME (2001) Diabetes mellitus. A hypercoagulable state. J Diabetes Complications 15:44-54

16. Finotti P, Carraro P, Calderan A (1992) Purification of proteinase-like and $\mathrm{Na}^{+} / \mathrm{K}^{+}$-ATPase stimulating substance from plasma of insulin-dependent diabetics and its identification as $\alpha 1$-antitrypsin. Biochim Biophys Acta 1139: 122-132

17. Sandler M, Stewart RI, Gemperly BM, Hanekom C, Kühn H (1987) Serum alpha-1-protease inhibitor activity and pulmonary function in young insulin-dependent diabetic subjects. Respiration 52: 281-289

18. Hu SI, Carozza M, Klein M, Nantermet P, Luk D, Crow RM (1998) Human HtrA, an evolutionarily conserved serine protease identified as a differentially expressed gene product in osteoarthritic cartilage. J Biol Chem 273:34406-34412

19. Erlanger BF, Kokowsky N, Cohen W (1961) The preparation and properties of two new chromogenic substrates of trypsin. Arch Biochem Biophys 95:271-278

20. Watanabe H, Tanase S, Nakajou K, Maruyama T, KraghHansen U, Otagiri M (2000) Role of Arg-410 and Tyr-411 in human serum albumin for ligand binding and esteraselike activity. Biochem J 349: 813-819

21. Finotti P, Pagetta A, Ashton T (2001) The oxidative mechanism of heparin interferes with radical production by glucose and reduces the degree of glycooxidative modifications on human serum albumin. Eur $\mathrm{J}$ Biochem 268:2193-2200

22. Pinna LA, Donella A, Clari G, Moret V (1976) Preferential dephosphorylation of protein bound phosphorylthreonine and phosphorylserine residues by cytosol and mitochondrial "casein phosphatases". Biochem Biophys Res Commun 70:1308-1312
23. Li Z, Srivastava PK (1993) Tumor rejection antigen gp96/grp94 is an ATPase: implications for protein folding and antigen presentation. EMBO J 12:3143-3151

24. Rosser MFN, Nicchitta CV (2000) Ligand interactions in the adenosine nucleotide-binding domain of the Hsp90 chaperone, Grp94. I. Evidence for allosteric regulation of ligand binding. J Biol Chem 275:2279822805

25. Wallin RPA, Lundqvist A, Moré SH, Bonin A von, Kiessling R, Ljunggren H-J (2002) Heat shoch proteins as activators of the innate immune system. Trends Immunol 23:130-135

26. Nicchitta CV (1998) Biochemical, cell biological and immunological issues surrounding the endoplasmatic reticulum chaperone GRP94/gp96. Curr Opin Immunol 10:103-109

27. Suzue K, Zhou X, Eisen HN, Young RA (1997) Heat shock fusion proteins as vehicles for antigen delivery into the major histocompatibility complex class I presentation pathway. Proc Natl Acad Sci USA 94:1314613151

28. Binder RJ, Blachere NE, Srivastava PK (2001) Heat shock protein-chaperoned peptides but not free peptides introduced into the cytosol are presented efficiently by major histocompatibility complex I molecules. J Biol Chem 276:17163-17171

29. Linderoth NA, Popowicz A, Sastry S (2000) Identification of the peptide-binding site in the heat shock chaperone/ tumor rejection antigen gp96 (Grp94). J Biol Chem 275:5472-5477

30. Li Z, Menoret A, Srivastava P (2002) Role of heat-shock proteins in antigen presentation and cross-presentation. Curr Opin Immunol 14:45-51

31. Asea A, Rehli M, Kabingu E, et al. (2002) Novel signal transduction pathway utilized by extracellular Hsp70. J Biol Chem 277:15028-15034

32. Lee AS (2001) The glucose-regulated proteins: stress induction and clinical applications. Trends Biochem Sci 26:504-510

33. Elias D, Markovits D, Reshef T, Van Der Zee R, Cohen IR (1990) Induction and therapy of autoimmune diabetes in the non-obese diabetic (NOD/Lt) mouse by a $65-\mathrm{kDa}$ heat shock protein. Proc Natl Acad Sci USA 87:15761580

34. Burkart V, Liu H, Bellmann K et al. (2000) Natural resistance of human beta cells toward nitric oxide is mediated by heat shock protein 70. J Biol Chem 275:1952119528

35. Faccio L, Fusco C, Chen A, Martinotti S, Bonventre JV, Zervos AS (2000) Characterization of a novel serine protease that has extensive homology to bacterial heat shoch endoprotease HtrA and is regulated by kidney ischemia. J Biol Chem 275:2581-2588

36. Ménoret A, Li ZL, Niswongers ML, Altmeyer A, Srivastava PK (2001) An endoplasmic reticulum protein implicated in chaperoning peptides to major histocompatibility of class I is an aminopeptidase. J Biol Chem 276:3331333318

37. Wassenberg JJ, Reed RC, Nicchitta CV (2000) Ligand interactions in the adenosine nucleotide-binding domain of the Hsp90 chaperone, Grp94. II. Ligand-mediated activation of Grp94 molecular chaperone and peptide-binding activity. J Biol Chem 275:22806-22814

38. Sastry S, Linderoth N (1999) Molecular mechanism of peptide loading by the tumor rejection antigen/heat shock chaperone grp96 (GRP94). J Biol Chem 274:1202312035 
39. Wearsh PA, Nicchitta CV (1996) Endoplasmic reticulum chaperone Grp94 subunit assembly is regulated through a defined oligomerization domain. Biochemistry 35:16760 16769

40. Smýkal P, Hrdý I, Pechan PM (2000) high molecular-mass complexes formed in vivo contain smHSPs and HSP70 and display chaperone-like activity. Eur J Biochem 267:21952207

41. Brunati AM, Contri A, Muenchbach M, James P, Marin O, Pinna LA (2000) GRP94 (endoplasmin) co-purifies with and is phosphorylated by Golgi apparatus casein kinase. FEBS Lett 471:151-1554
42. Berwin B, Reed RC, Nicchitta CV (2001) Virally induced lytic cell death elicits the release of immunogenic GRP94/ gp96. J Biol Chem 276:21083-21068

43. Melnick J, Aviel S, Argon Y (1992) The endoplasmatic reticulum stress protein GRP94, in addition to BiP, associates with unassembled immunoglobulin chains. J Biol Chem 267:21303-21306

44. Singh-Jasuja H (2000) Cross-presentation of glycoprotein 96-associated antigens on major histocompatibility complex class I molecules requires receptor-mediated endocytosis. J Exp Med 191:1965-1974 